\title{
EN MEMORIA DE EDUARDO RIPOLL PERELLÓ (1923-2006)
}

\author{
Ana María Muñoz Amilibia \\ Catedrática emérita de Prehistoria. UNED
}

No puedo, ni quiero, dejar de contribuir, aunque sea muy brevemente, al homenaje póstumo que dedica la UNED al que fue hasta su jubilación como profesor emérito, uno de sus miembros mas destacados entre los profesores de Historia, y, mas concretamente, de Prehistoria. El "no puedo", responde a mi sincero agradecimiento, ya que cuando vine a ocupar su plaza en 1990, me encontré con todo el Departamento bien organizado, y no tuve mas que continuar una labor en marcha. Esto era especialmente importante porque, después de pasar veinticinco años en universidades presenciales, la universidad a distancia era un auténtico reto. Eduardo Ripoll estuvo al frente de la Cátedra de Prehistoria de la UNED desde su creación, y, en 1988, al iniciarse la revista de la Facultad, Espacio, Tiempo y Forma, se dedicaron como homenaje al Dr. Ripoll sus dos primeros tomos de las Secciones de Prehistoria e Historia Antigua, respectivamente. También le fue dedicado como homenaje el volumen correspondiente a los tomos VII/VIII (1988-1989) de la revista Ars Praehistórica, creada por él mismo, y editada por la editorial Ausa de Sabadell con la colaboración de la UNED. La calidad científica y el afecto que se refleja en los trabajos de los participantes en estos homenajes dedicados cuando ya emérito, todavía tenía muchos años por delante, son la mejor expresión de la consideración y respeto que su trabajo y su persona habian obtenido a nivel internacional.

El año 2006 fue especialmente luctuoso para el arte rupestre de nuestra Prehistoria. En marzo fallecía, a los 82 años, en Barcelona, el Dr. Ripoll y, en abril, a los 90, don Antonio Beltrán. Más tarde, cuando aún estaba en activo, en pleno verano, falleció Pilar Acosta. Todos ellos fueron, junto con Francisco Jordá, los pilares de la investigación del arte rupestre en la segunda mitad del siglo XX, en todas sus facetas: paleolítico, levantino y esquemático. Representan el final de una etapa difícilmente superable, al menos en la intensidad y calidad de los trabajos, su actualización y nuevas orientaciones metodológicas.
No me siento capaz de comentar, y mucho menos valorar los trabajos, de Eduardo Ripoll, sino mas bien recordar algunos aspectos de su trayectoria humana. Compartí aulas en los últimos años de licenciatura (1953-54) con Eduardo y Luisa Ripoll, en la Universidad de Barcelona. Ellos estaban casi siempre en París, trabajando con Breuil, ordenándole montones de documentación, a veces inédita, y siguiendo sus orientaciones para redacción de su tesis doctoral sobre El arte Paleolítico español, que le dirigía Martín Almagro. En aquella época, los estudiantes de Historia de la Universidad de Barcelona fuimos muy afortunados, pues tuvimos grandes maestros. Vicens Vives con su equipo (Reglá, Nadal, Giralt, Mercadé), Alberto del Castillo con el suyo (Manuel Riu, Milicua), Mateu Llopis, Luis Pericot, Martín Almagro y Pedro de Palol. Disponiamos también de buenas bibliotecas universitarias (la Central y las de los departamentos), del Ateneo, de museos y la Biblioteca Central de la Diputación. Lo que no teniamos eran libros propios, había muy pocos en el mercado. Tampoco había fotocopias, era la época del "ciclostil". Como los profesores no se contentaban con los viejos manuales (Apolo) o grandes colecciones (Gallach), había que ir a sacar fichas de los libros de las bibliotecas. Menos mal que no había muchos alumnos en Historia, y sí mucho compañerismo entre ellos. Así establecíamos turnos horarios para los libros, que respetábamos religiosamente, de forma que no soltábamos el libro hasta que viniera el siguiente, para que no se nos colara nadie. Las fichas se almacenaban cuidadosamente en cajas de zapatos. Era un sistema muy práctico y barato y se aprendía mucho.

La estancia en París junto al maestro Breuil fue decisiva para Ripoll y sus discípulos, que de él aprendieron a hacer calcos y a estudiar las superposiciones estratigráficas. La casa de Breuil era un auténtico santuario del arte rupestre, llena de libros, papeles y rollos, fruto de su enorme trabajo de campo sobre todo en España, y todavía hoy permanece en mí el recuerdo agradecido y enorme afecto, que despertó en 
nosotras cuando le visitamos con M. ${ }^{\text {a }}$ Luisa Pericot y su padre. Para mi fue verdaderamente una experiencia inolvidable. Para Ripoll, como se refleja en el libro que le dedicó, su magisterio fue decisivo. El suyo era el método verdaderamente arqueológico para el estudio del arte rupestre, que supuso un gran avance frente a los análisis simplemente estilisticos, que ahora parecen ponerse de moda de nuevo, junto a los de interpretación chamánica. Creo recordar que Ripoll defendió su tesis doctoral en 1956 y que fue la primera que se celebró en la Universidad de Barcelona, ya que hasta entonces se tenía que hacer en la Universidad Central de Madrid.

Era difícil encontrar un trabajo compatible con los estudios, y Pericot y Almagro nos ayudaban dentro de sus posibilidades, con becas y ayudas de viaje del CSIC. Pero al final, después de hacer muchos méritos y eventualidades, había que hacer oposiciones, sobre todo si se quería hacer el doctorado. Había dos posibilidades, el Museo Arqueológico y la Universidad. En el Museo se ocupaban temporalmente los puestos más curiosos dentro del funcionariado de la Diputación, de la que dependía el Museo, hasta que, tras las correspondientes oposiciones, ganó la plaza de Conservador del Cuerpo de Museos, llegando a ser Director del Museo de Barcelona y más tarde del Arqueológico Nacional en Madrid. Mi ruta fue por distintos derroteros: oposición a institutos de enseñanza media y continuidad en la universidad como ayudante gratuita de clases prácticas hasta terminar el doctorado. Ripoll entró en la Universidad Autónoma de Barcelona, como agregado de Prehistoria, compatibilizando la actividad académica con la museística, que tras su traslado a Madrid, continuó en la UNED y el Museo Arqueológico Nacional. En ambas actividades destacarían dos facetas importantes: su magisterio formando discípulos que seguirían estudios de doctorado y su gran capacidad de editor y gestor. Son numerosos los discípulos que han continuado sus orientaciones y actualmente se dedican a arte rupestre. Sus publicaciones son numerosas, pero también su gestión organizando reuniones científicas y congresos, que siempre conseguía publicar. Desde la revista Ampurias, del Museo de Barcelona a los boletines de los museos hasta nuestra ETF, a la que ya me he referido, y los Congresos Internacionales del Estrecho de Gibraltar. Otra obra que quisiera destacar es su capacidad para análisis biográficos. Buena muestra fue su biografía de Breuil y las numerosas publicadas en necrológicas y artículos. Lamentablemente no tuvo tiempo de publicar la biografía de su otro maestro Luis Pericot García, lo que lamento de verdad, pues nadie podrá hacerlo como él.

\section{Bibliografía}

Gómez Barrera, Juan A. 2006: Dr. D. Eduardo Ripoll Perelló (1923-2006). Cuadernos de Arte Rupestre Centro Regional de Interpretación de Arte Rupestre (Moratalla), № 3, págs 216-217.

PALOL P. DE, 1988: Laudatio E.Ripoll Perelló, Espacio, Tiempo y Forma n 1 págs. 19-25.

Ripoll LóPeZ, SergIO, 1988-89; Presentación. Ars Praehistórica VII-VIII, Editorial Ausa, Sabadell. 